\title{
The development of Mechanical property and Hydration Characteristics of concrete at negative temperature environment
}

\author{
Yunbi Zhang ${ }^{1, \mathrm{a}}$, Hui $\mathrm{Li}^{2, \mathrm{~b}}$, Yu Xiong ${ }^{2, \mathrm{c}}$, Guangying Miao ${ }^{3, \mathrm{~d}}$, Yubing $\mathrm{Hu}^{1, \mathrm{e}}$,
}

\section{Honggen Qin ${ }^{2, f}$}

${ }^{1} \mathrm{JSTI}$ Group Co.,Ltd. The state key laboratory on safety and health of in-service long-span bridges, Nanjing; 211112, China;

${ }^{2}$ School of Materials Science and Engineering Southeast University, Nanjing; 211189, China;

${ }^{3}$ Highway construction administration bureau, Xining; 810008, China.

a006382@jsti.com, b673937982@qq.com, 1139129602@qq.com ;

d304586347@qq.com; ${ }^{\mathrm{f}} 101000881 @$ seu.edu.cn

Key words: Negative temperature; High performance concrete; Mechanical properties; Hydration Abstract: The development of the concrete mechanical properties and the characterization of hydration degree of the high performance concrete under negative temperature curing condition in plateau environment were studied. The results indicate that the concrete casted at the temperature below $-10^{\circ} \mathrm{C}$ must be mixed with the early strength antifreeze admixture with the optimum dosage, and other thermal insulation curing measurements should be taken at the same time. The process of concrete setting and hardening can be promoted, and the early strength can be increased. The strength of c30 concrete mixed with antifreeze admixture increases slowly under the negative temperature. Even though the samples are transferred into standard curing condition after being cured under the negative temperature condition for $3 \mathrm{~d}$ and $7 \mathrm{~d}$, the concrete strength are still lower than the concrete cured under the standard condition with the identical age, the 56d concrete strength of negative temperature are close to the $28 \mathrm{~d}$ strength of standard curing concrete. The effect of the negative temperature curing in the early stage on the development of concrete hydration degree is similar to the effect on compressive strength. The relation between the hydration degree and maturity degree is established, and the hydration degree can be predicted through the maturity degree of concrete under different curing conditions.

With the further advancement of "the Belt and Road Initiatives", the development of the traffic engineering in western region especially in Qinghai-Tibet Plateau becomes the vital factor of increasing regional accessibility and promoting the integration of western economy and optimization of resource allocation, furthermore the traffic engineering is closely related to the concrete engineering construction ${ }^{[1,2]}$. The annual period of negative temperature lasts for a long time in Qinghai-Tibet Plateau, and the negative temperature has an adverse effect on the construction, hydration and curing processes ${ }^{[3]}$. Therefore, besides the basic concrete mechanical properties, the concrete should offer suitable early strength, frost resistance, crack resistance and impermeability under the negative or even negative temperature. Therefore, study of the development of concrete mechanical properties and hydration degree under negative temperature 
curing condition in plateau environment is of great necessity.

\section{Introduction of the test}

\section{Testing materials}

$\mathrm{P} \bullet \mathrm{O} 42.5$ cement from Qilian Mountains in Qinghai Province, class $1 \mathrm{fly}$ ash; river sand from Qinghai Province, of which the fineness modulus is 3.5, the mud content is 3.6\%; crushed limestone with gradation of $5 \sim 31.5 \mathrm{~mm}$; all the properties of the above materials meet the standards requirements. The admixtures include antifreeze admixture water reducer and air-entraining agent, their basic properties are presented in Table 1.

Table1.Properties of admixtures

\begin{tabular}{ccccc}
\hline Admixture & $\rho(\mathrm{g} / \mathrm{cm} 3)$ & PH & Solid content $(\%)$ & Water reducing rate $(\%)$ \\
\hline Antifreeze admixture & 1.08 & 6.3 & 33 & - \\
Water reducer & 1.11 & 6.1 & 13.6 & 28 \\
Air entrancing agent & 1.02 & 6.0 & 35 & - \\
\hline
\end{tabular}

\section{Testing program}

In order to determine the optimum dosage of antifreeze admixture at $-10^{\circ} \mathrm{C}, 4$ mix proportions were designed, the 4 groups are numbered as F0,F3,F4,F5, indicating the antifreeze dosage of $0 \%$ 、 $3 \% 、 4 \%$ and $5 \%$ respectively. The mix proportions are presented in Table 2.

Table2. Mix proportion of concrete

\begin{tabular}{cccccccc}
\hline NO. & W/B & W & FA $(\%)$ & Sp $(\%)$ & PCA $(\%)$ & A-Q $(\%$ o & A-F (\%) \\
\hline F0 & 0.40 & 165 & 20 & 39 & 1.00 & 0.1 & 0 \\
F3 & 0.40 & 165 & 20 & 39 & 1.00 & 0.1 & 3 \\
F4 & 0.40 & 165 & 20 & 39 & 1.00 & 0.1 & 4 \\
F5 & 0.40 & 165 & 20 & 39 & 1.00 & 0.1 & 5 \\
\hline
\end{tabular}

Note: Sp is the sand proportion, PCA is poly carboxylate based plasticizer, A-Q is air-entraining agent, A-F is anti-freeze agent 。

For further study the concrete mechanical properties under different curing conditions, another 5 mix proportions were designed. Group $\mathrm{C}$ is the standard curing concrete without anti-freeze; group CA, AT, AT3 and AT7 have the optimum dosage after the optimization. Group CA adopted the standard curing, AT adopted the negative temperature curing, AT3 adopted negative temperature curing for 3 days ,then being transferred to standard curing, AT7 adopted negative temperature curing for 7 days then being transferred to standard curing. The negative temperature is set at $-10^{\circ} \mathrm{C}$.

\section{Testing method}

According to standard testing method of mechanical properties of ordinary concrete (GB/T50081-2002), the mechanical properties were tested at the prescribed age with the corresponding curing conditions. The TG-DSC was performed by model STA449 F3 simultaneous thermal analyzer produced by German company Rich.

\section{Results and Discussion}

The influence of antifreeze dosages on the mechanical properties of negative temperature concrete

The concrete was prepared according to the mix proportions in Table 2, and the samples were 
cured with mold at $-10^{\circ} \mathrm{C}$, after the curing, the compressive strength with different ages were tested, the results are presented in Table 3.

Table3. Concrete compressive strength with different dosages of antifreeze admixture at $-10^{\circ} \mathrm{C}$

\begin{tabular}{cccc}
\hline NO. & $3 \mathrm{~d}$ & $7 \mathrm{~d}$ & $28 \mathrm{~d}$ \\
\hline F0 & 0.0 & 0.4 & 3.6 \\
F3 & 1.2 & 5.0 & 11.0 \\
F4 & 1.7 & 7.5 & 12.8 \\
F5 & 0.8 & 5.1 & 12.0 \\
C & 19.8 & 33.6 & 42.3 \\
\hline
\end{tabular}

The testing results indicate that at $-10^{\circ} \mathrm{C}$, the $7 \mathrm{~d}$ and $28 \mathrm{~d}$ compressive strength of $\mathrm{c} 30$ concrete without mixing antifreeze decreased by $98.8 \%$ and $91.5 \%$ respectively ,compared to the concrete cured in the standard curing condition. While the compressive strength just decreased by $77.7 \%$ and $69.7 \%$ respectively with the $4 \%$ antifreeze admixture, which indicates that the negative temperature has a great effect on the concrete setting and hardening, the concrete hydration developed slowly under the negative temperature. The concrete without antifreeze admixture have the lower strength, the $3 \mathrm{~d}$ compressive strength is 0 however, and the strength get great improvement after adding the antifreeze, among them the antifreeze dosage of $4 \%$ has the greatest effect on improving the strength.

\section{The influence of curing conditions on the concrete mechanical properties}

Adopted the concrete with the optimum antifreeze dosage of $4 \%$ as the research object, the influence of negative temperature curing for $3 \mathrm{~d}$ and $7 \mathrm{~d}$ on the development of concrete mechanical properties during the early stage of hydration process is studied by changing the curing conditions. The testing results are presented in Table 4.

Table4. Compressive strength of concrete under combined curing conditions (MPa)

\begin{tabular}{clllll}
\hline curing age & $3 \mathrm{~d}$ & $7 \mathrm{~d}$ & $28 \mathrm{~d}$ & $56 \mathrm{~d}$ \\
\hline $\mathrm{C}$ & & 19.8 & 33.6 & 42.3 & 48.9 \\
$\mathrm{CA}$ & & 22.1 & 34.3 & 39.1 & 44.3 \\
\hline $\mathrm{X}$ is curing age in $-10^{\circ} \mathrm{C}$ & $-\mathrm{X}$ & $-\mathrm{X}+3 \mathrm{~d}$ & $-\mathrm{X}+7 \mathrm{~d}$ & $-\mathrm{X}+28 \mathrm{~d}$ & $-\mathrm{X}+56 \mathrm{~d}$ \\
\hline AT3 & 2.4 & 18.5 & 27.1 & 34.1 & 38.8 \\
AT7 & 7.5 & 17.7 & 21.6 & 36.2 & 40.4 \\
\hline
\end{tabular}

The testing results indicate that with the increase of curing age, the compressive strength improves; the strength develops much faster during the first 7 days, and develops slowly in the later stage. The concrete strength of the 2 groups(C and CA) with standard curing increase much faster with a higher affluence coefficient of $28 \mathrm{~d}$ strength. The concrete in group CA with $4 \%$ antifreeze admixture dosage have an obvious effect on early strength, the $3 \mathrm{~d}$ and $7 \mathrm{~d}$ compressive strength are much higher than the concrete in group C without antifreeze admixture, while the $28 \mathrm{~d}$ and $56 \mathrm{~d}$ compressive strength have a slight decrease compared with group C. The concrete in group AT3 and AT7 were added with antifreeze and cured under negative temperature, the strength also increase at $-10^{\circ} \mathrm{C}$ with a much higher strength in $7 \mathrm{~d}$ compared to $3 \mathrm{~d}$ however, it increases very slowly; Even the samples were transferred to the standard curing after the negative temperature curing for $3 \mathrm{~d}$ or $7 \mathrm{~d}$, the concrete strength are still lower than the standard cured concrete with the identical age, which indicates that the negative temperature curing in the early stage has a negative effect on the concrete early strength. The concrete with antifreeze admixture casted and cured at negative 
temperature, even after being transferred to standard curing condition, the early strength of which is still being influenced greatly, the $28 \mathrm{~d}$ compressive strength reaches the designed strength, while the affluence coefficient is much lower. The $56 \mathrm{~d}$ compressive strength are close to the $28 \mathrm{~d}$ concrete compressive strength with standard curing, which meet the requirements of the design.

\section{Characterization of hydration degree of negative temperature concrete}

Different curing conditions play a role in the hydration process of concrete, which influence the cement concrete macro mechanical properties together with the microscopic morphology and structure of hydration products. The main products of cement hydration are calcium silicate, calcium hydroxide and calcium aluminate hydrate. Because the cement hydration degree is proportional to the content of calcium aluminate hydrate produced by the cement hydration process ${ }^{[6]}$, we can indirectly obtain the cement hydration degree by identifying the content of calcium aluminate hydrate in cement mortar. The ratio of the calcium aluminate hydrate content measured in each group to the content of $28 \mathrm{~d}$ concrete under the standard curing condition is the hydration degree. The samples taken from the core part in the concrete were analyzed by STA. The endotherm of each sample is related to different temperature, and each endotherm is related to the corresponding quality change of samples in the TG chart ${ }^{[4-7]}$. Based on the loss weight rate, the changes of different phases are calculated, and the results are presented in Table 5.

Table5. Phase content of different concrete mix (\%)

\begin{tabular}{ccccccc}
\hline phase & C 28d & CA 28d & C 7d & AT3 -3d & AT7 -7d & $\begin{array}{c}\text { AT3 } \\
-3+7 d\end{array}$ \\
\hline $\mathrm{Ca}(\mathrm{OH})_{2}$ & 33.87 & 32.23 & 24.96 & 5.99 & 5.92 & 22.52 \\
Degree of hydration & 100.0 & 95.1 & 73.7 & 17.7 & 17.5 & 66.5 \\
\hline
\end{tabular}

Based on the TG analysis, compared to the concrete hydration degree with standard curing for $28 \mathrm{~d}$ in group C, the concrete with antifreeze in group CA have a $28 \mathrm{~d}$ hydration degree of $95.1 \%$, which is close to the concrete hydration degree without mixing antifreeze. After being cured at $-10^{\circ} \mathrm{C}$ for $3 \mathrm{~d}$ and $7 \mathrm{~d}$, the hydration degree reaches to $17.7 \%$ and $17.5 \%$ respectively, the negative temperature curing in the early stage has a greater impact on the concrete hydration degree, after being transferred to the standard curing conditions for $7 \mathrm{~d}$ after the negative temperature curing for $3 \mathrm{~d}$, the hydration degree increases to $66.5 \%$, which is still lower than the $7 \mathrm{~d}$ hydration degree $(73.7 \%)$ of the concrete under the standard curing condition, and the growth patterns of hydration degree shows the same pattern with the compressive strength.

\section{The maturity degree theory of negative temperature concrete}

The concrete maturity degree is proposed by saul based on the correlation of concrete strength and curing time as well as the curing temperature, I.e.

$\mathrm{Ms}=\sum(\mathrm{T}+10) \cdot \Delta \mathrm{t}$.

However, the negative temperature concrete cannot fit this formula well. Therefore, equivalent age maturity degree model is introduced ${ }^{[8-10]}$, this formula comprehensively considers the factors such as temperature, age and cement varieties, the functional relationship between concrete maturity degree and strength is inspected, temperature and maturity degree are reflected in the formula. The functional relationship between strength and maturity is expressed by power function, and the strength formula of concrete with fly ash in the test is: 
Fcu, $1=10.76 \mathrm{M} 1^{0.331}$.

in the formula $\mathrm{M} 1$-new maturity, $\mathrm{M} 1 \leq 20160\left({ }^{\circ} \mathrm{C} \cdot \mathrm{h}\right)$;

Fcu, 1 -relative strength(the percentage of the strength at a certain age and $28 \mathrm{~d}$ strength) the values put into the formula are in the form of percentage , fcu, $1 \leq 100$ 。

The maturity degree is calculated by putting the measured compressive strength into the above strength formula, the values are presented in Table 6.

Table 6. Maturity degree of negative temperature concrete $\left({ }^{\circ} \mathrm{C} \cdot \mathrm{h}\right)$

\begin{tabular}{ccccc}
\hline Maturity degree & & $3 \mathrm{~d}$ & $7 \mathrm{~d}$ & $28 \mathrm{~d}$ \\
\hline $\mathrm{C}$ & & 1796.88 & 8128.32 & 20195.28 \\
CA & & 3467.28 & 11964.72 & 19434.72 \\
\hline & $(-\mathrm{X})$ & $(-\mathrm{X}+3 \mathrm{~d})$ & $(-\mathrm{X}+7 \mathrm{~d})$ & $(-\mathrm{X}+28 \mathrm{~d})$ \\
\hline AT3 & 28.32 & 2026.32 & 6420.48 & 14027.52 \\
AT7 & 114.00 & 1796.88 & 3235.68 & 15397.92 \\
\hline
\end{tabular}

The results indicate that with the increase of the curing age, the maturity degree increases, the 2 groups(C and $\mathrm{CA}$ ) with standard curing increase much faster in its maturity degree. The concrete in group CA with $4 \%$ antifreeze admixture dosage has an obvious effect on early strength, the $3 \mathrm{~d}$ and $7 \mathrm{~d}$ compressive strength are much higher than the concrete in group $\mathrm{C}$ without antifreeze admixture, while the $28 \mathrm{~d}$ and $56 \mathrm{~d}$ compressive strength have a slight decrease compared to group C. The concrete in group AT3 and AT7 were added with antifreeze admixture and cured under negative temperature, the $3 \mathrm{~d}$ concrete maturity degree with negative temperature curing are much lower than the maturity degree of the concrete with standard curing at the same age, the maturity degree shows an obvious improvement after the concrete are transferred to the standard curing condition, but is still lower than the concrete with standard curing. The development of maturity degree is similar to the development of concrete strength, so predicting the concrete strength by using the maturity degree theory is feasible. This is of great guiding significance in predicting the concrete early strength under different curing conditions.

\section{The relational model of hydration degree and maturity degree}

In order to obtain the relation between hydration degree and maturity degree, and simplify the procedure of predicting the hydration degree, the data in Table 5 and Table 6 are function fitted to obtain the relationship as presented in Figure 1.

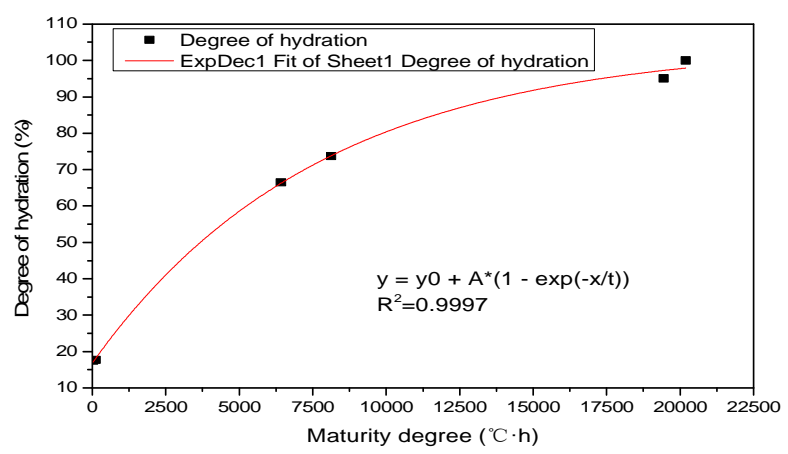

Figure.1. Relationship of maturity degree and hydration

The fitting results indicate that the relation between maturity degree and hydration degree fits well in with an exponential function, and the fitting correlation reaches to 0.9998 . The formula is 


$$
y=y 0+A^{*}(1-\exp (-x / t))
$$

Where $\mathrm{X}$ is maturity, $\mathrm{y}$ is hydration degree, $\mathrm{y} 0$ and $\mathrm{A}$ are all constants, and $\mathrm{y} 0$ is the hydration degree of the concrete at the beginning of molding, A and $t$ are correlation coefficients, their values are -87.46 and 7708.99 respectively. The application of this relational model lies in calculating the hydration degree by the concrete maturity degree under different curing conditions.

\section{Conclusions}

Based on the practical engineering project in Qinghai province, the test studies the developmental of mechanical properties and hydration degree of negative temperature concrete in plateau environment, conclusions are reached as follows by the overall evaluation of the testing results:

(1) The negative temperature has a significant effect on the concrete setting and hardening as well as the early strength. The concrete casted at the temperature below $-10^{\circ} \mathrm{C}$ must be mixed with the early strength antifreeze admixture with the optimum dosage, and other thermal insulation curing measurements should be taken at the same time.

(2) Under negative temperature, even though the samples are transferred into standard curing after being cured under the negative temperature for $3 \mathrm{~d}$ and $7 \mathrm{~d}$, the concrete strength is still lower than the concrete cured under the standard condition with the identical age , the $56 \mathrm{~d}$ strength of negative temperature concrete are close to the $28 \mathrm{~d}$ strength of standard curing concrete.

(3) The negative temperature curing in the early stage has significant effect on the concrete hydration degree, even though being transferred to the standard curing, the concrete hydration degree under negative temperature is still lower than the concrete hydration degree under standard curing with the identical age, and the development of it is similar to the development of compressive strength.

(4) The relation between hydration degree and maturity degree is established, and the hydration degree can be predicted through the concrete maturity degree under different curing conditions.

\section{Acknowledgments}

This work was financially supported by the Qinghai science and technology planning project, project number: 2014-GX-209.

\section{References}

[1] Hideo Kasami, Yoshiaki Tanaka, et al. Properties of concrete at very negative temperatures[C] Proceedings of the 1st International Conference. London: Construction Press, 1982:198

[2] Yang Linhu, Han Zhu, Li Cheng fang. Strengths and flexural strain of CRC specimens at negative temperature [J].Constr Build Mater, 2011(2):906

[3]Wang B., Li F. H., Li J. L., et al. Erosion-resisting characteristics of concrete under freeze-thaw action [J].Applied Mechanics and Materials,2013(1):351-352.

[4] Yong-Jinzhou you-guang li. The thermal analysis curves and characteristics of silicate hydration products [J]. Journal of Chongqing university of architecture, 1999 (01): 70-74.

[5] Xiao-chun li, sheng-xing wu. Based on the hydration degree of thermal analysis of the concept of early concrete [J]. Science, technology and engineering, 2008 (02): 441-445.

[6] He Xiaofang. Thermal analysis and research progress of cement hydration products [J]. Journal 
of silicate bulletin, 2012 (5): 1170-1174.

[7] Mounanga, P., et al. Predicting $\mathrm{Ca}(\mathrm{OH})_{2}$ content and chemical shrinkage of hydrating cement pastes using analytical approach[J]. Cem. Concr. Res, 2004. 34(2): 255-265.

[8] Guo when Ann. Rapid simplified weight maturity method to predict the concrete compressive strength [J]. Concrete, 2015 (12): 145-147.

[9]jian-li liu, rilem tc, Li Fei. Use concrete early strength of the new concept of maturity prediction [J]. Journal of construction technology, 2006 (8): 68-70.

[10]Benaicha M, Burtschell Y, Alaoui A H. Prediction of compressive strength at early age of concrete - Application of maturity [J]. Journal of Building Engineering, 2016, 6:119-125. 